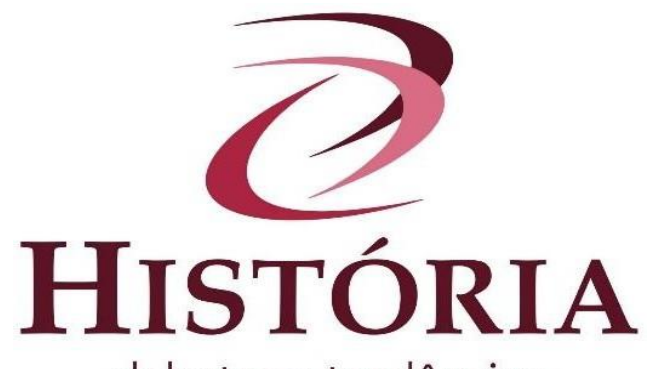

\title{
A peste aporta em Santos e Rio de Janeiro
}

\section{Plague arrives in Santos and Rio de Janeiro}

\author{
Llega la peste a Santos y Río de Janeiro
}

Dilene Raimundo do Nascimento*

\begin{abstract}
Resumo: Neste artigo, serão examinados alguns aspectos importantes do matizado processo de construção da narrativa científica sobre a peste bubônica em duas cidades portuárias brasileiras, nas quais o impacto de uma epidemia ocasionou e impulsionou tanto um forte debate em torno da doença quanto a busca de soluções científicas e sanitárias para as graves consequências locais de sua erupção. Essas duas cidades portuárias, a cidade de Santos, no estado de São Paulo, Brasil, e Rio de Janeiro, capital da República Federativa do Brasil, constituem-se não como loci passivos de uma epidemia mortal, mas como cenas privilegiadas de um intenso debate e de importantes experimentações em saúde pública, fundamentais para o controle do surto epidêmico, para construção de uma imagem da doença e para elaboração de um protocolo de conhecimento do mal.
\end{abstract}

Palavras-chave: Brasil. Epidemia. Peste.

\begin{abstract}
In this article, some important aspects of the nuanced process of building the scientific narrative about bubonic plague in two Brazilian port cities will be examined, in which the impact of an epidemic caused and spurred both a strong debate around the disease and the search for scientific solutions and sanitary for the serious local consequences of its eruption. These two port cities, the city of Santos, in the state of São Paulo, Brazil, and Rio de Janeiro, capital of the Federative Republic of Brazil, constitute themselves not as passive loci of a deadly epidemic, but as privileged scenes of an intense debate ch for scientific solutions. and sanitary for the serious local consequences of its eruption. These two port cities, the city of Santos, in the state of São Paulo, Brazil, and Rio de Janeiro, capital of the Federative Republic of Brazil, constitute themselves not as passive loci of a deadly epidemic, but as privileged scenes of an intense debate and important experiments in public health, essential for the control of the epidemic outbreak. , to build an image of the disease and to elaborate a protocol for knowledge of evil.
\end{abstract}

Keywords: Brazil. Epidemic. Plague.

Resumen: En este artículo se examinarán algunos aspectos importantes del matizado proceso de construcción de la narrativa científica sobre la peste bubónica en dos ciudades portuarias brasileñas, en el que el impacto de una epidemia provocó y estimuló tanto un fuerte debate en torno a la enfermedad como la búsqueda de soluciones científicas y sanitario por las graves consecuencias locales de su erupción. Estas dos ciudades portuarias, la ciudad de Santos, en el estado de São Paulo, Brasil, y Río de Janeiro, capital de la República Federativa de Brasil, se constituyen no como lugares pasivos de una epidemia 
mortal, sino como escenarios privilegiados de intenso debate. e importantes experimentos en salud pública, imprescindibles para controlar el brote epidémico, construir una imagen de la enfermedad y elaborar un protocolo sobre el conocimiento del mal.

Palabras clave: Brasil. Epidemia. Peste.

\section{A peste aporta em Santos e Rio de Janeiro}

Em comum a essas duas cidades, bem como, a outros locais de incidência epidêmica, está o fato de apresentarem um longo histórico de surtos patológicos. Até os inícios do século XX, era comum nessas cidades a mortalidade infantil, a morte materna em função de infecções pós-parto, um verdadeiro rosário de doenças, como o raquitismo, o sarampo, a difteria, a meningite, entre outras, que levavam à morte um número incalculável de crianças, além de uma sucessão de males que acometiam os adultos, ceifando-lhes a vida, numa idade em que ainda poderiam produzir (ALMEIDA, 2012).

Portanto, não há de se estranhar que especialmente essas cidades portuárias fossem palco de agressivos surtos epidêmicos de peste negra, febre amarela, cólera, varíola, entre outras doenças. E foi, justamente em função dessas trágicas realidades comuns, que se desenvolveram, simultânea e circularmente, em cada uma dessas localidades, estratégias de higiene e saúde pública que, associadas à observação, às práticas laboratoriais, enfim, aos embates e pesquisas científicas acabarão por resultar em avanços no combate e/ou no controle desses males epidêmicos.

A partir da segunda metade do século XIX, ocorreriam notáveis progressos na medicina e em áreas que viriam alimentar os programas de saúde pública. As mudanças na Saúde Pública seriam sustentadas pelos progressos na Microbiologia que levariam a mudanças profundas nas práticas médicas. Com a identificação dos agentes patogênicos microbianos, que respondiam pela maior parte das doenças contagiosas, que até então acometiam as sociedades europeias, foi possível construir uma compreensão maior da propagação das doenças, bem como melhorar o seu combate. Nesse contexto, a peste que incidia na cidade do Porto, em Portugal, no ano de 1899, constituiu-se num importante momento tanto de prova para os novos conhecimentos em progresso, quanto para o ensaio de avanços na busca de soluções para os problemas de saúde pública, provocados por sua erupção. 


\section{A peste em Santos}

E da cidade do Porto atravessando o Atlântico, uma nova erupção da doença aportou em Santos, em certa medida, repetindo os dilemas já vivenciados em Portugal, ao mesmo tempo, inaugurando uma nova fase na pesquisa em busca do combate efetivo ao patógeno pestífero. Em agosto de 1899, o Governo brasileiro foi notificado da ocorrência da peste na cidade do Porto e tomou medidas para prevenir sua entrada no país. Os navios vindos de portos portugueses a partir de $1^{\circ}$ de agosto estavam sujeitos a uma quarentena de 20 dias, antes de serem admitidos aos portos nacionais, além de submetidos a uma rigorosa desinfecção. A partir de 16 de agosto, estas medidas foram estendidas aos portos espanhóis. (NASCIMENTO, 2011) Apesar de todas as medidas de prevenção adotadas pelo governo do estado de São Paulo em consonância com o governo federal, apareceram em 15 de outubro, na cidade de Santos, os primeiros "casos de uma enfermidade grave de sintomatologia estranha e similar à peste bubônica" (NASCIMENTO, 2011, p. 72).

Designados a investigar o evento, Adolfo Lutz e Vital Brasil, respectivamente, diretor e assistente do Instituto Bacteriológico de São Paulo, lançando mão de métodos e conceitos oriundos do Instituto Pasteur, diagnosticam as enfermidades como casos de peste bubônica.

O Ministério da Justiça e Negócios Interiores, ao ser notificado do resultado da investigação dos dois cientistas, ordenou o imediato fechamento dos portos brasileiros a todos os navios provenientes do porto paulista. Tal medida objetivava circunscrever a extensão da doença ao porto de Santos, acabou por provocar a repetição em território brasileiro do que já ocorrera na cidade do Porto, quando da imposição da quarentena por Dr. Ricardo Jorge: o intenso debate político associado a protestos contra eventuais danos econômicos e sociais produzidos pela medida de quarentena.

Nuno de Andrade, diretor geral de Saúde Pública, em ofício dirigido ao governo, no qual, a par de descrever a situação sanitária dos estados brasileiros, solicitava a sua exoneração, dizendo-se "profundamente ferido pela infelicidade da cidade de Santos como funcionário e como cidadão brasileiro". Afligia-lhe a lembrança de que nos setenta dias anteriores à notificação da peste no Porto, os portos brasileiros tenham ficado desprotegidos. O pedido de demissão de Nuno de Andrade não foi aceito pelo governo que, motivado pela gravidade da situação, decidiu realizar uma contraprova dos resultados obtidos pelos cientistas de São Paulo, designando o bacteriólogo Oswaldo Cruz, recém chegado do Instituto Pasteur de Paris, para tal missão. 
Antes de continuarmos a descrever as medidas governamentais voltadas para o combate ao surto de peste bubônica em Santos, vale a pena caracterizar a importância deste porto na cena econômica nacional, bem como, recuperar mais detalhadamente a cronologia do surto epidêmico.

A cidade de Santos foi palco de uma grande mudança na segunda metade do século XIX. De pequena aldeia em 1870, tornou-se um polo econômico como o segundo maior porto do país em exportação do café. Santos tornar-se-ia brevemente, com a transferência do eixo cafeeiro do Vale do Paraíba Fluminense para o Oeste de São Paulo, no maior centro escoador da produção cafeeira, já nos alvores da República. Se em 1870, escoavam-se pelo porto daquela localidade 437.580 sacos de café, em 1899, 5.742.362 sacos de café eram por ali despachados. (Almanaque de Santos, Apud NASCIMENTO, 2011, p, 71).

Desde os seus inícios, o porto de Santos foi objeto de tentativas de reformas e melhorias. A Associação Comercial de Santos, fundada em 1870, representando os interesses das grandes companhias de importação e exportação, frequentemente, tentou resolver os problemas no fluxo de embarque e desembarque de mercadorias. Ao apelar para a iniciativa privada e governamental, a Associação Comercial, cujos presidentes, em sua maioria, foram produtores de café, sempre teve como objetivo primeiro o incremento das exportações cafeeiras. E foi com tal objetivo que o governo imperial licitou o controle do porto de Santos para investidores privados. Cândido Gafrèe e Eduardo Palassim Guinle ganharam a licitação e, em 1892, transformaram sua empresa na Companhia Docas de Santos. (HONORATO, 1996)

Some-se a isto a constante necessidade de mão de obra para as fazendas de café. O que fez com que o governo de São Paulo patrocinasse boa parte de toda imigração para aquela região:

\footnotetext{
a grande imigração que se organiza principalmente no segundo lustro da década de 1880 permitiu a extraordinária expansão dos cafezais que perdurou praticamente até a crise de 1929. Nos últimos anos do Império se definiu o processo de recrutamento do imigrante por parte da administração de São Paulo, organizando-se para isso toda uma infraestrutura para recebê-lo e distribuí-lo pelas fazendas de café. (PETRONI, 1985, p. 103).
}

No ano de 1899, o próprio ano do surto da peste no porto de Santos, o governo de São Paulo baixou uma lei, segundo a qual os imigrantes poderiam trazer para São Paulo qualquer pessoa de seu conhecimento em sua região de origem. Neste caso ainda, o governo se encarregaria de subsidiar a vinda dos interessados. Petroni transcreve citação de Pierre Denis que, a propósito da administração do governo de São Paulo da imigração 
subvencionada, observa: “(...) um mundo moderno tem visto poucos espetáculos semelhantes ao desse governo incumbir-se de importar, em massa, operários agrícolas." (PETRONI, 1996, p.108).

O fato é que o porto de Santos reflete o dinamismo da economia cafeeira e assim apresenta, a par de um grande esforço de modernização, um intenso fluxo de mercadorias e pessoas. Não foi à toa, portanto, que logo às primeiras notícias do surto pestífero no Porto/Portugal levaram o diretor geral de Saúde Pública, Nuno de Andrade, em função do intenso tráfego marítimo entre o porto de Santos e os portos portugueses e espanhóis a estabelecer uma quarentena para todas as embarcações provenientes de além-mar.

Em a Campanha Sanitária de Santos, suas causas e seus efeitos, edição do Serviço Sanitário do Estado de São Paulo/Casa Duprat), em 1919, Guilherme Álvaro da Silva ${ }^{\mathrm{i}}$ descreve com minúcias "tudo quanto se passou" desde sua chegada à cidade, em 18 de outubro de 1899:

\footnotetext{
Tendo ficado encarregado de dirigir o expurgo das casas que tivessem fornecido doentes de peste, e das autópsias dos cadáveres duvidosos, presenciamos todos os serviços, dali por diante, e nos lembraremos sempre do que vimos no prédio número 39 da Rua 15 de Novembro, cujos fundos davam para Rua 24 de Maio, sob o número 60. (SILVA, 1919, p. 5)
}

Aqui, baseados em sua narrativa, discutiremos os principais momentos do desenvolvimento do surto pestífero em Santos.

O governo brasileiro fora comunicado dos casos de peste no Porto em começo de agosto, a partir de então, as autoridades nacionais trataram de estabelecer medidas sanitárias de controle dos barcos procedentes de portos ibéricos. Contudo, em 22 de agosto chega a Santos o "Rei de Portugal", navio de procedência portuguesa que antes de atracar em Santos, fizera a escala no Rio de Janeiro. Coincidentemente ou não, em início de setembro, médicos santistas identificaram frequentes casos de adenites submaxilares em crianças que costumavam frequentar a região portuária. O Dr. Eduardo Lopes, chefe da Comissão de Saúde local, convida Vital Brasil do Instituto Bacteriológico de São Paulo, para estudar esses casos. Este último, nada de notável encontrou, salvo ingurgitamentos linfáticos, comuns em garotos. (SILVA, 1919, p. 5)

O Dr. Guilherme Álvaro continua sua narrativa, observando que, logo depois, em 17 de setembro, notificou-se à Secretária de Saúde de Santos um caso de febre amarela, ocorrido também na região do porto, mas cujo doente, já no segundo dia, encontrava-se às portas da morte. Os procedimentos adotados para a remoção do doente levaram à 
observação de que o caso evoluíra de maneira estranhamente rápida, além de o aspecto do cadáver em nada confirmar um diagnóstico de febre amarela. Ao contrário, a presença de um tumor na virilha direita fez com que o inspetor sanitário, encarregado do processo, solicitasse a opinião de outros médicos. De qualquer forma, o diagnóstico de febre amarela não se sustentou ao mesmo tempo em que se levantava a hipótese de um caso de peste. É curioso que, em seu relato, Dr. Guilherme Álvaro chama a atenção para o fato de que, àquele momento, o principal argumento contrário a possível caso de peste na cidade basear-se no pressuposto de sua absoluta inexistência na região. Para a realidade daqueles médicos, acostumados a responder com um conjunto de conhecimentos pré-estabelecidos aos fenômenos patológicos que compunham a sua realidade corriqueira, os sintomas, neste caso específico, não só destoavam de tudo que eles conheciam como não se apresentavam solidamente referenciados no seu universo de representação.

Ao mesmo tempo, as autoridades sanitárias santistas foram notificadas de um número anormal de ratos mortos nas proximidades tanto da casa do falecido quanto dos armazéns da Companhia Docas de Santos. Em fins de setembro, o Dr. Adolfo Lutz retorna a Santos, desta vez para colher material referente à mortalidade dos ratos. $\mathrm{O}$ cientista não obteve sucesso em suas pesquisas a ponto de oferecer uma solução para o mistério. Por outro lado, era comum verem-se nas ruas da cidade, ratos mortos envenenados ou mesmo caçados pelos comerciantes - o que conferia às ruas próximas ao cais um aspecto particularmente repugnante.

Embora não houvesse certeza quanto às causas e consequências da mortandade de roedores, o fato é que os inspetores da vigilância sanitária passaram a reforçar, especialmente à população mais pobre, habitantes dos arredores da região do porto, a necessidade dos cuidados com a higiene bem como a necessidade da caça aos roedores.

Dr. Guilherme Álvaro prossegue na sua narrativa, referindo-se aos ratos vistos no porto:

\footnotetext{
Podem ser vistos à noite, indo de terra para bordo dos navios e deles vindos para terra, numerosos ratos que transpõem com agilidade admirável os cabos fixadores das embarcações às muralhas do cais; deste modo as doenças desses animais, reinantes a bordo ou em terra, são facilmente conduzidas dum para outro lugar. (SILVA, 1919, p.7).
}

Segundo o relato do Dr. Guilherme, foi, a partir de um caso ocorrido no começo de outubro, que as autoridades médicas, tanto da cidade de Santos quanto do estado de São Paulo, passaram a conceber aqueles casos repentinos de doença e morte como indicadores 
de peste. Em 4 de outubro, a Comissão Sanitária foi informada de uma repentina morte por febre amarela "ocorrido quase subitamente, na véspera à noite, na rua de São Bento, próximo à estação da E. de Ferro" (Idem). Mais uma vez, o médico que assinava a notificação hesitava quanto ao exato diagnóstico a ser registrado. E mais uma vez, em 6 de outubro, o Dr. Vital Brasil volta a Santos para prosseguir as pesquisas em torno desses eventos fatais.

Já em 7 de setembro, a Comissão Sanitária era informada que na Santa Casa falecera um vitimado por fortíssima infecção, apresentando ingurgitamento de gânglios na virilha. O falecido morava em casa fronteira àquela do óbito, supostamente por febre amarela, ocorrido em setembro. Às medidas cabíveis seguiram-se um reforço no policiamento e na inspeção dos domicílios. A população em geral não acreditava na existência de um surto daquilo que era vulgarmente denominado de "bubônica". De qualquer modo, as inspeções continuaram e, em 14 de outubro, removeu-se para o isolamento uma mulher que trabalhava como empregada de família de uma casa de bebidas à Rua 15 de Novembro, $\mathrm{n}^{\circ} 39$. A edificação era um "prédio velho, cujos fundos davam para a rua 24 de Maio". E ainda desta vez, os sintomas da doente foram identificados como de febre amarela. Exames subsequentes resultaram, contudo, em outro diagnóstico, especialmente quando a doméstica passou a apresentar ingurgitamento ganglionar na virilha, “de onde o Dr. Vital Brasil retirou material para estudo". "As pesquisas do Dr. Vital Brasil resultaram em seguro conhecimento de ser a peste a doença causadora da mortandade dos ratos e dos óbitos rotulados de febre amarela, ocorridos desde setembro, sendo informado disso o governo do estado, pela diretoria do Serviço Sanitário".(SILVA, 1919, p. 7)

A este primeiro óbito da Rua 15 de Novembro, $n^{\circ} 39$, seguiu-se na mesma casa o adoecimento e consequente óbito de outro empregado, além do de um morador na Rua Amador Bueno, recolhido ao isolamento com febre alta e delírio. Toda a família da Rua 15 de Novembro, n 39, acabou removida para o hospital de isolamento e a Comissão Sanitária “estendeu as desinfecções com creolina a todo o quarteirão, composto de casas velhas, de tipo ultra viciosas, com solo desprotegido, cheias de cubículos escuros, onde os ratos eram abundantes”. O Dr. Guilherme Álvaro completa, assim, a imagem referencial de uma representação científica das condições propícias ao surto pestífero.

Ainda segundo Guilherme Álvaro, o governo federal, notificado do surto pestífero em Santos em 17 de outubro, reforçou a Comissão Sanitária local com o envio de 6 inspetores sanitários. Dividiu-se a cidade em 12 distritos, "de modo a cada prédio ser visitado de 5 em 5 dias, sendo inspecionados diariamente os moradores das zonas que 
haviam fornecidos doentes suspeitos".

Armou-se uma verdadeira operação de guerra aos ratos em defesa da cidade com a distribuição de veneno, o incentivo ao uso de ratoeiras, além da veiculação de uma campanha de informação que alertava a população para o perigo oferecido por tais animais, cujas pulgas, vetores da doença, deviam ser destruídas com o uso de creolina. Além dessas medidas, criou-se todo um sistema de controle sanitário, pelo qual, a entrada e saída de pessoas da cidade implicava a desinfecção de bagagens e cargas direcionadas a outras regiões do estado de São Paulo. Para os que saiam da cidade de Santos, criou-se um serviço de "passaportes sanitários", pelos quais, os provenientes daquela localidade eram submetidos a uma semana de controle e exames nas regiões a que se destinavam. Enfim, Santos, seu porto e sua população apareciam, desde então, como cidadela inexpugnável contra a peste.

Nessa altura de seu relato, o Dr. Guilherme Álvaro da Silva introduz incidentalmente duas questões que merecem uma atenção mais detida; e neste caso, cabe aqui a reprodução integral da passagem que as contém:

\footnotetext{
A Câmara Municipal de Santos, para acalmar o povo, desorientados com os conselhos de alguns médicos e, de muitos entendidos, que não acreditavam na peste, e depois que o governo do estado havia tomado todas as providências, resolveu mandar do Rio de Janeiro, ganhando quantia elevada, um bacteriologista para estudar a doença reinante na cidade.(...)

Em alguns dias os seus estudos estavam feitos e em conferência sensacional, porquanto o resultado oposto era esperado pelos entendidos, concordou com o veredicto do Instituto Bacteriológico de São Paulo, apontando ser necessário tomar-se medidas radicais contra o mal, inclusive o expurgo pelo fogo, de todas as casas contaminadas.

Desse dia em diante, a municipalidade apoiou decididamente a Comissão Sanitária, a que seis médicos por aquela subsidiados prestaram muito bons serviços, sendo aumentada a zona de policiamento sanitário rigoroso.
}

Ao mesmo tempo, a Câmara aumentava o pessoal da limpeza, pública, que ficou perfeitamente organizada, realizando um serviço irrepreensível durante todo o tempo que durou a doença.

\section{A peste no Rio de Janeiro}

O segundo porto deste lado do Atlântico, em território brasileiro, que foi palco de um surto pestífero, àquela época, foi o do Rio de Janeiro - o porto da Capital Federal. ${ }^{\text {ii }} \mathrm{O}$ porto do Rio de Janeiro, apesar de representar um elemento fundamental no desenvolvimento econômico da cidade, mostrava-se ainda profundamente arcaico tanto em 
seu funcionamento quanto em suas dimensões e instalações. No começo do século XX, a cidade do Rio de Janeiro, Capital da República, vivia um intenso processo de transformação. Sua população aumentava grandemente tanto em função da forte imigração europeia, particularmente a portuguesa, quanto pela chegada de famílias vindas do interior fluminense. Como resultado desse crescimento demográfico, a Capital Federal oferecia mão de obra barata em grande quantidade, além de um vasto mercado consumidor para os padrões da época, duas condições imprescindíveis para o nascente parque industrial local dedicado especificamente à produção têxtil, à produção de cerveja e a produção de tabaco.

Ocorre que, a par de todo desenvolvimento econômico da cidade e da posição estratégica de seu importante porto, a Capital Federal apresentava ainda feições extremamente arcaicas, com a maioria da sua população amontoada em cortiços ou casas de cômodos, nas áreas centrais da cidade e na região portuária. E refletindo o padrão de ocupação e más condições higiênicas das habitações observadas na cidade do Porto, a Capital Federal do Estado brasileiro mostrava-se também totalmente carente das mínimas condições sanitárias para a sua população pobre e trabalhadora.

Segundo a observação de Luiz Edmundo, em o Rio de Janeiro do meu tempo:

\begin{abstract}
O turista, que vem à América do Sul, muitas vezes, aqui, nem baixa à terra bárbara, do navio em que viaja, contentando-se com vê-la de longe, no quadro magistral da natureza, que não se pode estragar, porque, além de feia e desinteressante, a cidade é um perigo, foco das mais tremendas moléstias infecciosas: a febre amarela, a peste bubônica, a varíola. (1957, p. 25).
\end{abstract}

Enfim, a cidade do Rio de Janeiro era não apenas um "perigo" para os eventuais visitantes, como para a atividade comercial e industrial que aqui se desenvolvia. E seu porto, com sua precária estrutura, falta de saneamento, e arcaísmo no seu processo de funcionamento, mal dava conta do intenso tráfego de mercadorias que

\footnotetext{
ameaçava entupir a parte central [da cidade], dédalo de ruelas e becos sujos e mal calçados, fendas onde mal penetrava a luz do sol e pelas quais o bondezinho da Carris Urbanos, estreitíssimo, puxado por um só burro, desatava a correr e a pular como um cabrito, os passageiros sobrando pelos estribos e plataformas, entre carroças de todo gênero, carrinhos de mão, tilburis, e o poviléu vozeirudo e trapento (Idem, p.26).
}

Com todas essas características não há de se espantar que meses após o rápido e eficazmente debelado surto de peste em Santos, o mesmo fenômeno patológico viesse a ocorrer na Cidade de São Sebastião do Rio de Janeiro. A documentação disponível não permite até agora qualquer afirmação definitiva sobre como a peste chegou à Cidade do Rio 
de Janeiro. Mas se sabe, com considerável grau de certeza, onde e quando ocorreu o primeiro caso documentado:

[...] A sete de janeiro do corrente ano, [1900] foi denunciado às autoridades sanitárias, como suspeita de peste, um menino de nome Alcides, morador na Ladeira do Valongo, $\mathrm{n}^{\circ} 3$. O exame clínico, (...), deixou o diagnóstico incerto; e no dia imediato, agravando-se o estado do enfermo, procedeu-se a pesquisa bacteriológica pela qual se verificou a existência, (...) de bacilos semelhantes ao da peste. (...) imediatamente foi o doente removido para a enfermaria flutuante, e esta transladada para a enseada de Jurujuba, onde fundeou às sete horas da tarde. O infeliz menino agonizava já, e nenhum tratamento foi possível instituir. (...) No dia 13 , logo que foi conhecido o resultado dos trabalhos de laboratório, declarou o governo, oficialmente, a ocorrência de um caso de peste na Capital Federal. ${ }^{\text {ii }}$

Aparentemente, este primeiro caso de peste na Capital Federal teria sido debelado sem maiores dificuldades, graças às medidas sanitárias adotadas na localidade de seu aparecimento, a Ladeira do Valongo. O presidente à época, Campos Salles, chegou inclusive, a manifestar sua satisfação pela declaração, em maio de 1900, de que a cidade do Rio de Janeiro estava "limpa" da peste, o que refletia o sucesso no impedimento da propagação da moléstia, reduzida a "um caso isolado". iv Ora, o caso citado por Campos Salles não era absolutamente um caso isolado, mas sim, o primeiro entre vários que passaram a ocorrer na cidade, desde janeiro de 1900.

Seja como for, as medidas até então adotadas pelo governo na Capital Federal não conseguiram impedir os surtos epidêmicos que de 1900 em diante surgiam na cidade. De fato, as taxas oficiais de óbitos registradas entre 1900 e 1903 mostram justamente o contrário, isto é, de ano a ano a peste recrudescia na Capital Federal. v

Entre as causas para o insucesso das primeiras investidas oficiais contra a peste bubônica, na cidade do Rio de Janeiro, ao contrário do que afirmara Campos Salles em seu discurso diante do Congresso Nacional, podemos citar a falha na tentativa de extermínio dos ratos e suas pulgas, vetores da doença; a persistência das péssimas condições sanitárias, especialmente nas áreas próximas ao porto; a baixa notificação de casos às autoridades sanitárias, além do descompasso e desarticulações das ações dos órgão responsáveis pela saúde pública na cidade - a Diretoria Geral de Saúde Pública (DGSP), em nível federal, e a Diretoria de Higiene e Assistência Pública, em nível municipal ${ }^{\mathrm{vi}}$.

Refletindo já a experiência do surto anterior em Santos, criou-se, de imediato, como efetiva resposta institucional à doença, o Instituto Soroterápico Federal para produção de soro e vacina antipestosos no Brasil. ${ }^{\text {vii }}$

Diante da frustração das medidas empregadas no combate aos surtos anuais, em meados de 1903, o Governo Federal resolveu reformular toda a sua estratégia de combate à 
doença. Na verdade, esta nova posição vinha no bojo de um projeto de reestruturação do espaço urbano, higienização e modernização da Capital Federal e de seu porto, como condição sine qua non para transformação da imagem da cidade de aglomerado arcaico em cosmopolita metrópole capitalista, equiparada às grandes cidades europeias, em especial, Paris. Com a eleição, em 1902, de "um enamorado das belezas naturais da cidade" (EDMUNDO, 1957, p.26), Rodrigues Alves, rico cafeicultor de São Paulo, inaugura-se toda uma era de reforma, saneamento e modernização da, até então colonial, Capital Federal.

O projeto de modernização da Capital Federal, com vistas ao atendimento tanto dos interesses econômicos ligados ao porto quanto às aspirações da burguesia local de se sentir integrada ao circuito internacional das práticas civilizadas, enfim, com todos os signos da modernidade econômica, social e cultural, dependia de uma operação de saneamento/civilização do Rio de Janeiro que acabasse com as principais epidemias que lhe prejudicavam a economia e que denunciavam seu arcaísmo. (NASCIMENTO \& SILVA, 2013).

Rodrigues Alves, inteiramente dedicado à reforma e ao saneamento da Capital Federal, reuniu Pereira Passos, como prefeito da cidade, e Oswaldo Cruz, como diretor da DGSP, com a missão de debelar as epidemias que aqui grassavam.

Em que pesasse a sua formação em microbiologia pasteuriana, Oswaldo Cruz pautará toda a sua ação de combate aos males crônicos da cidade, numa perspectiva fundamentalmente sanitarista. Com os sucessos obtidos no combate à febre amarela, acrescenta-se, a partir de 1904, sua campanha contra a peste bubônica. Se, em princípio, Oswaldo Cruz recorreu à vacinação da população portuária contra a doença, o médico não deixou de lado práticas sanitaristas clássicas como a notificação obrigatória, o isolamento de doentes, a remoção de entulhos e reformas das habitações, além de outras medidas de saneamento urbano, como a limpeza das vias públicas.

Uma das medidas mais bem sucedidas, à época, foi a famosa compra de ratos. À imposição aos funcionários da DGSP de apresentação mensal de certa quantidade de ratos mortos, somou-se uma gratificação de 300 réis por roedor. Além disso, passou-se a oferecer certa quantia em dinheiro ao cidadão que levasse à diretoria um rato morto. Num primeiro momento, a caça aos ratos mostrou-se estratégia eficaz na prevenção dos surtos pestíferos. Mas, com o tempo, perdeu sua eficácia, em função da ação de espertalhões que passaram a criar tais animais com o intuito de vendê-los à DGSP.

A peculiaridade da Cidade do Rio de Janeiro na história das epidemias de peste bubônica está no fato de, com o fim do surto em 1907, a cidade não mais ser atingida por 
qualquer manifestação desta doença. Uma possível explicação para tal peculiaridade está na ação conjunta da DGSP, sob a direção de Oswaldo Cruz, e Pereira Passos, à frente da então Capital Federal, e sua política de modernização da zona portuária e do centro da cidade. As ações articuladas desses dois gestores resultaram na melhoria das condições de funcionamento do porto do Rio de Janeiro, na abertura de novas vias de comunicação no centro da cidade, com destaque para a principal artéria da região, a Avenida Central — hoje Avenida Rio Branco - , na valorização da Capital Federal como metrópole moderna e "civilizada", de acordo com padrões internacionais e, ancilarmente, na melhoria das condições gerais de saúde do povo simples.

Observe-se, contudo, que a razão última das ações sanitaristas de Oswaldo Cruz, articuladas à reforma urbana imposta por Pereira Passos, não foi a melhoria das condições de vida da população que margeava a Baía de Guanabara. Antes, tratava-se de responder às graves questões sanitárias que comprometiam o alto comércio internacional praticado no porto do Rio de Janeiro, periclitando, assim, os interesses econômicos e políticos do Estado brasileiro. Os eventuais ganhos para a saúde pública, isto é, para a saúde dos mais pobres, aparecem assim como efeitos colaterais positivos de um projeto econômico e político de modernização econômica do país, melhoria de sua imagem no exterior e elaboração de uma autoimagem favorável de si mesmo, da parte das elites locais.

\section{Comentários finais}

Em resumo, dois portos e uma mesma resposta ao fenômeno da peste. A importância do exame dos surtos pestíferos em Santos e no Rio de Janeiro fica demonstrada pela similitude de alguns aspectos marcantes nessas duas situações distintas. Nos dois portos a peste bubônica faz sua aparição quase que magicamente já que em nenhum dos casos examinados foi possível uma determinação precisa de sua origem. Na cidade de Santos e no Rio de Janeiro as autoridades locais mostraram-se capazes de reconstituir com precisão a gênese dos respectivos surtos epidêmicos. Por outro lado, nos dois portos o epicentro da epidemia localizou-se nas regiões miseráveis adjacentes ao cais, atingindo diretamente indivíduos que ali habitavam. Nos dois casos, as autoridades locais mostraram-se incapazes ou reticentes na identificação dos primeiros casos de adoecimento e morte das vítimas da peste.

As regiões imediatamente circunvizinhas aos portos, nas duas cidades, constituíamse de logradouros miseráveis habitados, maiormente, por trabalhadores portuários, 
pequenos comerciantes e mesmo desocupados que viviam dos restos das atividades econômicas desenvolvidas no cais. Por seu turno, os grandes empresários ligados diretamente às atividades importadora e exportadora e, portanto, altamente interessados no pleno funcionamento portuário negam no primeiro momento a admitir a existência de qualquer evento patológico que pudesse implicar a suspensão, ainda que temporária, de suas altamente lucrativas atividades comerciais. No caso do porto de Santos, por exemplo, a Companhia Doca, a par do zelo documentado em relatório oficial, com as melhorias materiais no funcionamento do porto, não demonstrou, em momento algum, qualquer interesse em adotar medida de quarentena, ainda que provisória, como um dos métodos adequados de combate ao surto epidêmico. Já na Capital Federal, a providencial e imediata resposta às más condições da região portuária, foi a promoção de uma arrasadora reforma urbana e saneamento, que, embelezando a região central da cidade, interiorizou as camadas pobres da população, o que acabou por resultar naturalmente na destruição dos focos propícios ao surgimento e propagação da peste bubônica.

Nos dois portos, nas duas cidades, podemos observar o espetáculo das difíceis e, ainda que eventualmente, produtivas relações entre os poderes políticos, econômicos e científicos, entre negacionismos, interesses divergentes e soluções de compromisso. No caso do alto empresariado ligado às atividades portuárias, a imediata resolução positiva do surto epidêmico seria imprescindível para a manutenção e a expansão da acumulação capitalista, sem os entraves, empecilhos, desgastes e prejuízos, eventualmente, provocados por devastadoras crises sanitárias. Para o poder político, resolver uma crise epidêmica da importância da que acometia os dois portos, significava não apenas a afirmação de sua capacidade de controle social, como também de manutenção e ampliação dessa capacidade em favor dos interesses maiores do Estado Nacional.

\section{Referências}

ALMEIDA, Maria Antonia Pires de. O Porto e as epidemias: saúde e higiene na imprensa diária em períodos de crise sanitária, 1854-56, 1899 e 1918. Revista de História da Sociedade e da Cultura, 2012.

BENCHIMOL, Jaime Larry. Pereira Passos: um Haussmann tropical: a renovação urbana da cidade do Rio de Janeiro no inicio do século $X X$. Rio de Janeiro: Departamento Geral de Documentação e In-formação Cultural, 1990.

EDMUNDO, Luiz. O Rio de Janeiro do meu tempo. $2^{\text {a }}$ edição, Rio de Janeiro, Editora Conquista, 1957. 
HONORATO, Cezar. O polvo e o porto: a Cia. Docas de Santos (1888-1914). São Paulo; Hucitec; 1996.

NASCIMENTO, Dilene R. do ; SILVA, Matheus Alves Duarte. A peste bubônica no Rio de Janeiro e as estratégias públicas no seu combate (1900-1906). Revista Territórios \& Fronteiras, Cuiabá, vol. 6, n. 2, jul.-dez., 2013.

NASCIMENTO, Dilene R. do.La llegada de la peste al Estado de Sao Paulo en 1899. Dynamis, vol.31 (1), p. 65-83, 2011.

PETRONI, Maria Tereza Schorer. Imigração. In: História Geral da Civilização Brasileira, sob a direção de Sérgio Buarque de Holanda. O Brasil Republicano. São Paulo: Difel, 1985, tomo III.

SILVA, Guilherme Álvaro. A campanha sanitária de Santos - Suas causas e seus efeitos (edição do Serviço Sanitário do Estado de São Paulo/Casa Duprat), 1919.

Recebido em 20/08/2020

Aprovado em 10/10/2020

Publicado: $1 \% 101 / 2021$

\footnotetext{
${ }^{*}$ Médica. Doutora em História Social pela Universidade Federal Fluminense. Pesquisadora em História das Doenças e docente no Programa de |Pós-Graduação em História das Ciências e da Saúde da Casa de Oswaldo Cruz/Fiocruz.

'Guilherme Álvaro da Silva nasceu no Rio de Janeiro em 1869 e faleceu em São Paulo em 1930. Diplomouse em Ciências Médicas e Cirúrgicas em 1891. Atuou como irmão e médico da Santa Casa da Misericórdia por 27 anos. (Mariela Izolan. Instituto Dona Scholastica Rosa (1899-1933) a partir do olhar de Júlio Conceição. Dissertação de Mestrado em Educação na Universidade Católica de Santos, 2013, p.28).

ii $\mathrm{O}$ porto do Rio de Janeiro era considerado um dos 15 maiores do mundo à época. De principal exportador do café brasileiro no século XIX, transformou-se na principal porta de entrada de produtos importados para o Brasil. O porto da cidade do Rio de Janeiro também era "parada obrigatória para navegação de cabotagem que ligava o Norte ao Sul do país" (BENCHIMOL, Jaime Larry. Pereira Passos: um Haussmann tropical: a renovação urbana da cidade do Rio de Janeiro no inicio do século $X X$. Rio de Janeiro: Departamento Geral de Documentação e In-formação Cultural, 1990, p. 219).

iii Relatório apresentado ao presidente da República dos Estados Unidos do Brazil, pelo doutor Epitácio Pessoa, ministro da Justiça e Negócios Interiores, em março de 1900, p. 362-363.

iv Mensagem apresentada ao Congresso Nacional, na abertura da $1^{\mathrm{a}}$ Sessão da $4^{\mathrm{a}}$ Legislatura, pelo presidente da República, M. Ferraz de Campos Salles, p.19.

v Em 1900, registraram-se 295 óbitos; em 1902, 215 e 360 em 1903.

vi A DGSP, órgão de nível federal, respondia pela defesa marítima, o isolamento e a desinfecção de navios suspeitos; já à DHAP correspondia o combate à doença em terra, bem como a eliminação de seus eventuais focos.

vii A produção do soro antipestoso no Brasil começou justamente no período de combate ao surto de peste bubônica em Santos e no Rio de Janeiro. Em Santos, a necessidade de aplicação de soro aos casos existentes e a consequente constatação de sua quantidade insuficiente, pois que o fármaco dependia de sua importação direta do Instituto Pasteur/Paris, levou os cientistas envolvidos no combate à doença - Oswaldo Cruz e Vital Brasil, entre outros - a tomar a iniciativa de criação de uma instituição nacional dedicada à pesquisa e produção de soro e vacina antipestosos. Foi, portanto, neste contexto de crise sanitária em Santos e no Rio de Janeiro que nasceram o Instituto Soroterápico de São Paulo (Instituto Butantã) e o Instituto Soroterápico Federal (Instituto de Manguinhos).
} 